\title{
Des établissements « branchés » - II
}

L'opération « Savoirs-Collège » en France

Centre national de documentation pédagogoqie (CNDP)

\section{CpenEdition}

Journals

Édition électronique

URL : http://journals.openedition.org/ries/2913

DOI : $10.4000 /$ ries.2913

ISSN : 2261-4265

Éditeur

Centre international d'études pédagogiques

Édition imprimée

Date de publication : 1 juin 1998

Pagination : 72-73

ISSN : $1254-4590$

Référence électronique

Centre national de documentation pédagogoqie (CNDP), «Des établissements « branchés » - II », Revue internationale d'éducation de Sèvres [En ligne], 18 | juin 1998, mis en ligne le 19 avril 2013, consulté le 26 avril 2019. URL : http://journals.openedition.org/ries/2913 ; DOI : 10.4000/ries.2913

Ce document a été généré automatiquement le 26 avril 2019

(c) Tous droits réservés 


\title{
Des établissements « branchés » - II
}

\author{
L'opération « Savoirs-Collège » en France
}

Centre national de documentation pédagogoqie (CNDP)

\begin{abstract}
Les technologies numériques avec le site Internet (www.cndp.fr) et plusieurs cédéroms permettent un accès direct à des ressources multiples grâce à des moteurs de recherche conçus à partir des termes mêmes des programmes officiels d'enseignement du collège.

Les besoins professionnels étant formulés, l'enseignant est orienté vers les ressources traditionnelles existantes (livres, articles de revues...) et/ou vers les plus récentes (émission de télévision, cédéroms, sites Internet...).

\section{Origine}

L'opération a été initiée en septembre 1997 par le CNDP/réseau, en liaison avec les directions pédagogiques du ministère, la direction de l'Information scientifique, des Technologies nouvelles et des Bibliothèques, la direction de l'Évaluation et de la Prospective et l'inspection générale.

\section{Dispositif}

Cette offre nouvelle de services proposés aux enseignants des collèges par le réseau CNDP/CRDP/CDDP comprend :

- une émission de télévision intitulée «Galilée " portant sur les disciplines suivantes des nouveaux programmes : technologie, sciences physiques, sciences de la vie et de la terre, français, géographie, arts plastiques, musique, éducation à la citoyenneté, à l'orientation et à la santé, des documents seront conçus à la rentrée prochaine pour d'autre disciplines : mathématiques, langues vivantes, histoire. Des documents d'accompagnement, accessibles en ligne ou édités sur livrets, sont conçues pour chaque émission ;

- des fiches pédagogiques mises à disposition sur le service Internet du CNDP ; - le signalement d'autres sites jugés adaptés aux objectifs des programmes des 
collèges ;

- des cédéroms distribués gratuitement à tous les collèges qui ne sont pas encore connectés.

\section{Objectifs}

Donner aux enseignants la possibilité :

- de se documenter grâce à une base de données construite pour être interrogée à partir des mots mêmes des nouveaux programmes des collèges ;

- de consulter des informations en permanence actualisées (textes réglementaires, arrêtés, circulaires..., références aux revues éducatives du CNDP, réponses précises concernant l'actualité éducative, l'organisation des enseignements, les dispositifs de soutien...) ;

- de dialoguer avec des collègues (rubrique Tribune/site Internet) de confronter des expériences, d'élaborer en commun des réponses ;

- de passer commande des productions du CNDP/réseau par l'intermédiaire de la cyberboutique.

\section{Évaluation}

- La mise en place d'un dispositif d'évaluation permettra prochainement de faire apparaitre un certain nombre d'indicateurs portant sur les pratiques d'utilisation et les attentes des enseignants.

INDEX

Index géographique : France

Mots-clés : collège, nouvelles technologies, programme de télévision, multimédia, pédagogie 